\title{
Pharmacy managers in the spotlight: time to stand up and be counted
}

\author{
Phil Wiffen
}

In this issue, we publish the results of the EAHP survey for sections 1, 3 and 4 of the EAHP statements. The results make interesting reading as they give a snapshot in time of the state of hospital pharmacy across Europe. There is much that is commendable, and the results show a desire for things to continue to move in the right direction.

The red warning light on the dashboard for me is the statement 'Not considered to be a priority by my managers'. This occurs a number of times and is made by a significant number of responders.

Being a pharmacy manager is not an easy task and frequently the skills acquired by managers are appreciated by the wider hospital management team so pharmacy managers are sucked into wider hospital management (and away from their core task). Alternatively, there is a temptation to settle for a quiet life and not challenge forceful and opinionated medical or management colleagues.

Responses relating to four statements raise concerns in terms of being low priority for managers:

The first (statement 4.4) relates to reconciling the medicines listed in the patients' medical record and an assessment on whether these medicines (and any herbal or dietary supplements) are appropriate. This assumes that pharmacists have access to such records, a battle that has been fought and won in many countries but is essential if pharmacists are going to perform to their potential. The assessment of herbal and dietary products and also over-the-counter medicines is an area often missed by junior doctors so important. Currently, only $29 \%$ of respondents stated that this statement is actioned. One hundred and fifty-eight responders stated that this area was not a priority for managers.

Statement 4.5 refers to the transfer of information about medicines when patients move between and within healthcare settings. While a positive response was higher than for statement 4.4 , it was

Correspondence to Professor Phil Wiffen, Pain Research Unit, Churchill Hospital, Oxford OX3 7LE, UK; phil.wiffen@ndcn.ox.ac.uk noted by the authors that the response was lower than the baseline survey. Twenty-eight per cent (126) stated that this was not a managerial priority.

Statement 4.8 is about the evolution of clinical pharmacy services to optimise patient outcomes. The positive response for this was 42\% (307 responders). Just over $61 \%$ of the negative responders $(257$ out of 453) stated that the development of clinical pharmacy services was not seen as a priority by managers or clinicians. Given the evidence that clinical pharmacy services reduce morbidity and mortality as well as save healthcare costs, this is a disappointing result. A small number of responders state that they have a strategic plan but that is not supported by their managers.

Clinical pharmacy, by its very nature, requires working as part of a multidisciplinary team, which is covered in statement 1.1. This statement refers to the hospital pharmacy service working collaboratively with other professions. Thirty-nine per cent (152 responders) stated that this was not a priority for pharmacy managers and $24 \%$ (95 responders) said this was not a priority for medical/nursing staff. It seems that many pharmacy managers are failing to recognise the strengths and opportunities of multiprofessional working.

There are caveats in that the number of responders in some countries was small, and in many cases responders felt that there was insufficient capacity to take on new roles. We can easily end up with a chicken or egg argument here. Once the case is made and new services (such as a basic clinical pharmacy on one ward) were initiated and proven (perhaps without additional funding), then resources invariably follow.

This paper should act as a 'wakeup' call for pharmacy managers especially those who recognise their own resistance to support clinical developments. There also appears to be a worrying 'disconnect' between managers and their more ambitious junior staff.

Hospital pharmacies need to be learning organisations able to identify and manage knowledge that will improve their status and role. Muir Gray ${ }^{1}$ summarises Peter Senge's approach in his book titled The Fifth Discipline: the art and practice of the learning organisation ${ }^{2}$ and identifies five disciplines. Four of these are:

- Personal mastery: the ability to continually clarify and deepen person vision and objectivity

- Building shared visions - the discipline of moving the vision from a few leaders to everyone in the organisation

- Team learning - the disciple to ensure that the collective wisdom of the team is greater than any one individual (even the manager!)

- Systems thinking: so that individual elements are linked together to provide a well-rounded service.

\section{SO WHAT NEEDS TO BE DONE?}

Time to move the focus away from the dispensary and from medicine charts to patients. Use technical support and technology to dispense medicines and free up pharmacists for wider clinical roles.

Time for pharmacy managers to take a lead in using the self-assessment and implementation tools linked to the statements.

Time for an honest conversation from those responders who feel unsupported with their managers to seek to change the culture.

It can be lonely at the top, so peer support is vital and where this has been established into an occasional meeting or event, it has proved to be valuable.

Above all, for some, it is time to stand up and be counted!

\section{Competing interests None declared.}

Provenance and peer review Commissioned; internally peer reviewed.

(C) European Association of Hospital Pharmacists (unless otherwise stated in the text of the article) 2017. All rights reserved. No commercial use is permitted unless otherwise expressly granted.

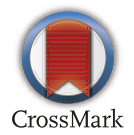

To cite Wiffen P. Eur J Hosp Pharm 2017;24:255.

Published Online First 5 August 2017

Eur J Hosp Pharm 2017;24:255.

doi:10.1136/ejhpharm-2017-001362

\section{REFERENCES}

1 Gary M. Evidence based Healthcare and Public Health Muir Gray. Elsevier, 2001. ISBN 9780443101236

2 Senge PM. The Fifth Discipline: The art and practice of the learning organization. Century Business, 1990. 